\title{
THE STRUCTURE AND PROPERTIES OF NEW THIOFLUOROPHOSPHATE GLASSES
}

\section{HAROUTUNIAN NORA M.}

Institute of General and Inorganic Chemistry of the National Academy of Sciences of Republic of Armenia, St. Erebouni 11, 30, Yerevan 41, 375041, Republic of Armenia

\begin{abstract}
Is investigated sulfur containing phosphate and fluorophosphate glasses on the base of barium metaphosphate and alkaline-earth fluorine in the $\mathrm{Ba}\left(\mathrm{PO}_{3}\right)_{2}-\mathrm{Na}_{2} \mathrm{~S}-\mathrm{MgF}_{2}$ systems. The replacement of oxygen by sulfur and fluorine in its systems bring to quantitative and qualitative changes of structural groupings. Polysulfuride $[-\mathrm{S}-\mathrm{S}-]$ and fluorine $\left[\mathrm{MeF}_{4}\right],\left[\mathrm{MeF}_{6}\right]$ groupings are formed, which promote essential change of barium metaphosphate glass skeleton, stabilization of glassy condition, and, accordingly, essential changes of physicochemical properties of glasses.
\end{abstract}

\section{INTRODUCTION}

The development of contemporary science and technology requires the formation of new inorganic materials, possessing with new complex of properties, perspective for different areas of technology. For new class technical material obtaining, having definite optical constants, relatively easiness to melt, high values of coefficient of linear thermal expansion, glassformation regions, properties and structure were investigated of sulfur containing phosphate and fluorophosphate glasses in $\mathrm{Ba}\left(\mathrm{PO}_{3}\right)_{2}$ $\mathrm{Na}_{2} \mathrm{~S}-\mathrm{MgF}_{2}$ systems. To reveal sulfur- and fluorine- composed influence on glass phosphate base and to work out compound of welding easy to melt glass with low spreading temperature for welding with metals.

\section{EXPERIMENTAL PROCEDURE}

The synthesis of glasses was carried out using reactive of "EC" mark in muffle

\footnotetext{
Received October 21, 1999; Accepted December 14, 2000
} 
furnace in glasscarbide crucible at $1100-1150{ }^{\circ} \mathrm{C}$ for 60 minutes, in dry argon atmosphere. The glasses have been thermo-treated at certain temperatures of crystallization obtained according to differential thermo-analysis. The differential thermo-analysis curves were obtained on derivatograph DQ-1000 with heat rate $10 \%$ min. Dilatometric characteristics were taken off on quartz dilatometer DKV-4A with heat rate $3 \% \mathrm{~min}$. Difractograms of glass crystallization products were taken off on $\ddot{A} \oplus \hat{I} I-1.5$ with copper beam and nickel filter use, survey rate was $2 \%$ min. Glasses viscosity in soften temperature interval was measured by cylinder indentor squeezing method on viscosimeter of Slavyanskiy. IR-spectrums of absorption were taken off by powder technology on spectrophotometer UR-20 in the field of $400-1500 \mathrm{~cm}^{-1}$.

\section{RESULTS AND DISCUSSION}

The results of investigation in the field of glass formation as well as a number of physico-chemical properties and structure of synthesized glasses are presented underneath.

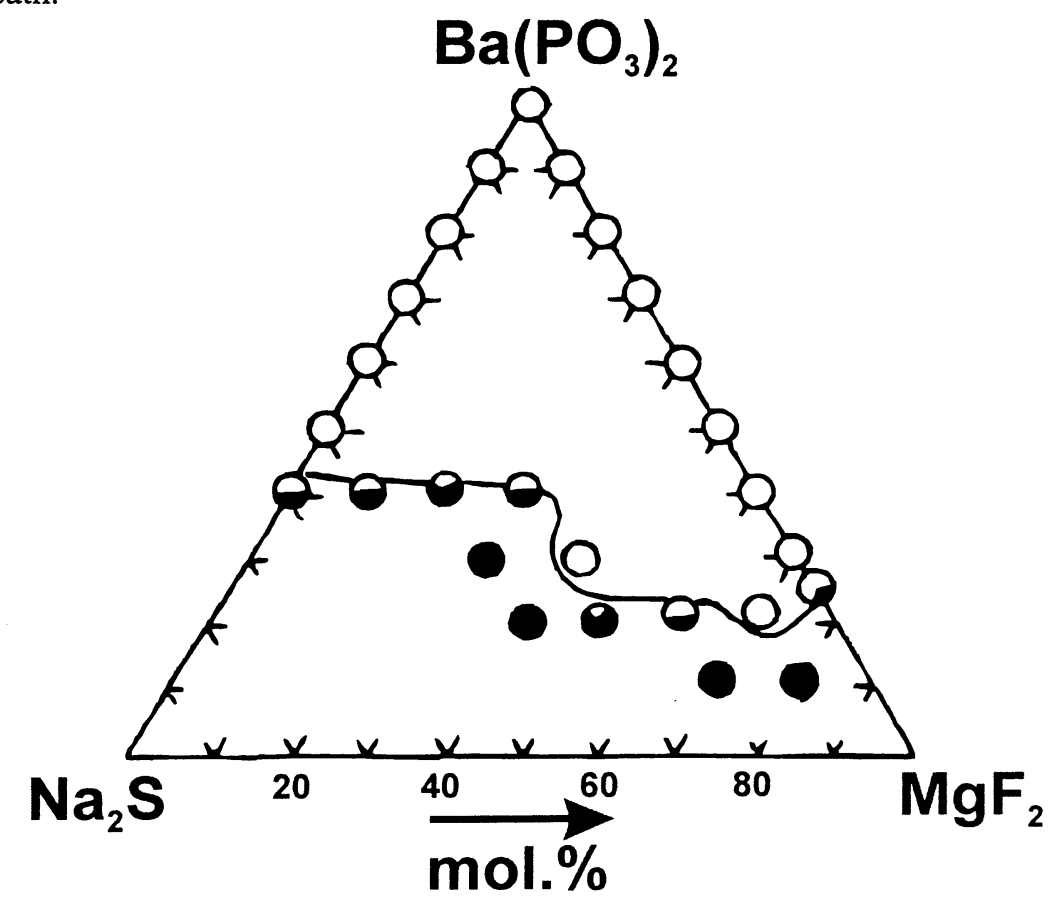

FIGURE1. Glassforming region in the $\mathrm{Ba}\left(\mathrm{PO}_{3}\right)_{2}-\mathrm{Na}_{2} \mathrm{~S}-\mathrm{MgF}_{2}$ system.

$O$ - transparent glass $\bullet$ - full crystallization 
Structural interpretation of properties dependencies on the chemical composition is offered. The condition of synthesis permit to obtain transparent losses no more than 60 mol. $\%$ of $\mathrm{Na}_{2} \mathrm{~S}$ content. A wide range of glass formation has been obtaining the limits of stable glasses having no tendency of liquation and crystallization have been determined (fig. 1).

Analyzing the data obtained as result of physico-chemical investigations by $\mathrm{X}$ ray phase analysis, IR-spectroscopy, DTA, coefficient of linear thermal expansion, density, refraction index, electrical properties, viscosity, chemical stability some assumption on the structural and physico-chemical properties peculiarities of the glasses under investigation have been made. ${ }^{1}$

By the character of chemical bonds the sulfur and oxygen are similar, somehow the polarization anion of $\mathrm{O}^{2-}$ is less then $\mathrm{S}^{2-}$, owing to what Me-S stronger, than Me-O. ${ }^{2}$ The covalent bonds of sulfur-metal have the certain orientation in glass melts and promote the glass formation more, than oxygen. ${ }^{3}$

The replacement of oxygen by sulfur in phosphate and fluorine phosphate systems bring to quantitative and qualitative change of structural groupings and to essential change of the structure of barium metaphosphate glass skeleton, and its physico-chemical properties of a glass.

The identification of glass crystallization products phases has shown, that in initial glass the basic product of crystallization is $\mathrm{Ba}\left(\mathrm{PO}_{3}\right)_{2}$. The presence of sodium sulfide and with growth of its contents the intensity of barium metaphosphate characteristic line is decreases and gradually occur the diffraction maximum concerning to $\mathrm{Ba}_{3}\left(\mathrm{PO}_{4}\right)_{2}, \mathrm{Ba}_{2} \mathrm{P}_{2} \mathrm{O}_{7}$ and $\mathrm{BaS}_{2}$. In the pseudo-triple system, in the composition multifluorine area the field of $\mathrm{BaMgP}_{2} \mathrm{O}_{7}, \mathrm{MgF}_{2}, \mathrm{Na}_{3} \mathrm{SO}_{4} \mathrm{~F}$ crystallization is only.

On IR-spectrum of an initial glass of barium metaphosphate structure there are absorption strips in the field of $1310-1260 \mathrm{~cm}^{-1}, 1160-1060 \mathrm{~cm}^{-1}, 1020-870 \mathrm{~cm}^{-1}, 770$ $670 \mathrm{~cm}^{-1}$ wavelengths which are stipulated with valence and deformative oscillations of P-O bonds, chained in metaphosphate fragments of $\left(\mathrm{PO}_{3}\right)$ n glasses (fig.2). The presence sodium sulfide essentially changes the glassy barium metaphosphate structure. The depolymerization of the chained phosphate groups follows in the phosphate of the glass lattice structure, reducing the strength of the structure. Intensity of the basic 
absorption lines are decreasing and shifting towards low wavelengths, which, actually,are connected to the decrease of the total content of phosphate of chains. The intencity of absorption growth in the field of wavelengths $1115-1100 \mathrm{~cm}^{-1}$ on the account of fluctuations $v_{\text {as }} \mathrm{PO}_{3}$ formed pirophosphate groups $\left(\mathrm{P}_{2} \mathrm{O}_{7}\right)$.

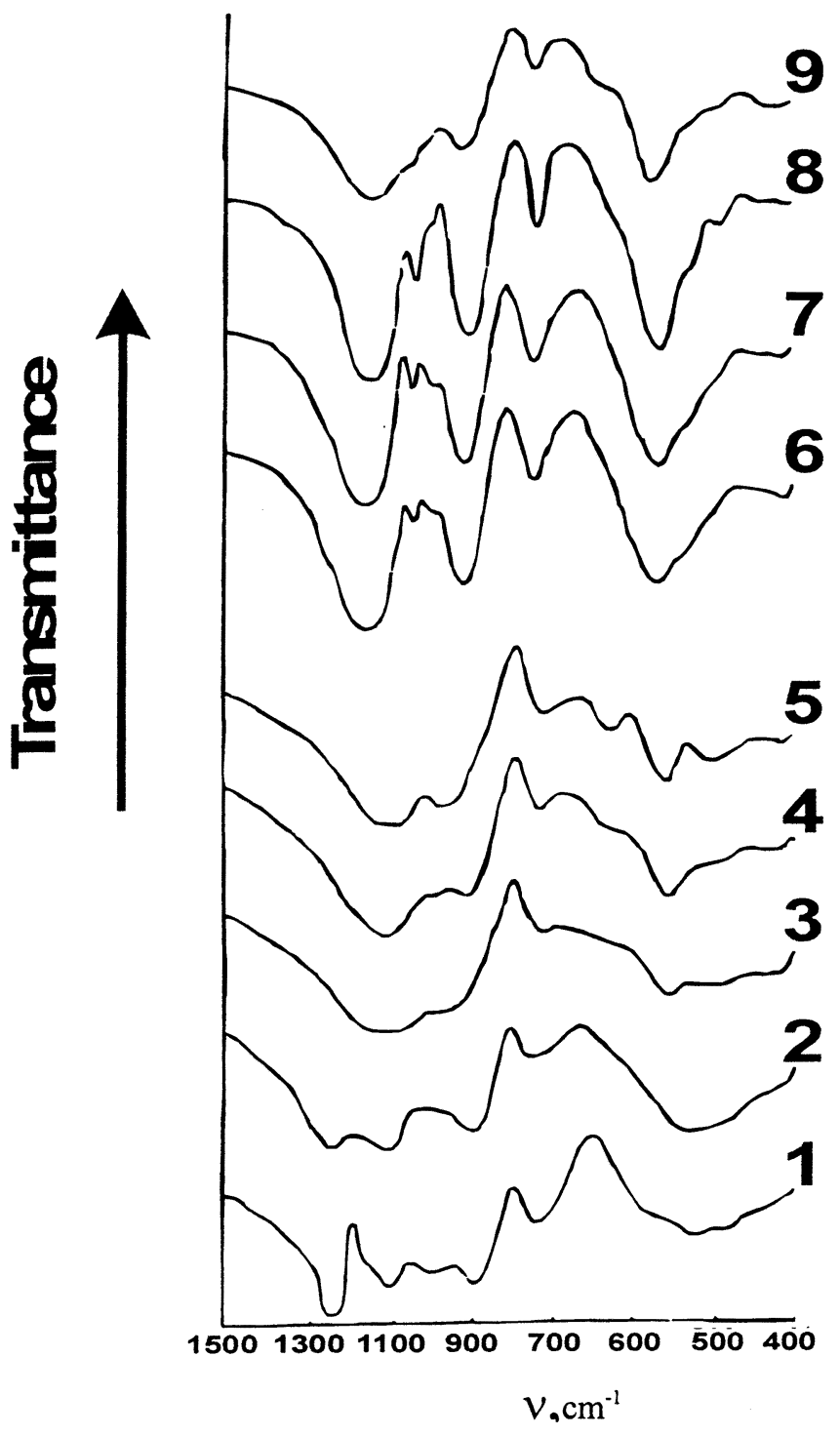

FIGURE 2. The absorption IR-spectra of investigated systems on slot 1 (1-5) and slot 2(6-9);

Slot $1-\mathrm{Ba}\left(\mathrm{PO}_{3}\right)_{2}-\mathrm{Na}_{2} \mathrm{~S}, 1-0 ; 2-10 ; 3-20 ; 4-30 ; 5-40 \mathrm{Na}_{2} \mathrm{~S}$ mol. \% content

Slot 2- $\mathrm{Ba}\left(\mathrm{PO}_{3}\right)_{2}=50$ mol. \% (const.), 6-10; 7-20; 8-30; 9-40 $\mathrm{Na}_{2} \mathrm{~S}$ mol.\% content 
Simultaneously, with growth of the contents sodium sulfide, in multisulfure area of structures, in spectra there are new strips of absorption in the field of wavelengths 630 $625 \mathrm{~cm}^{-1}$ and $530-470 \mathrm{~cm}^{-1}$ caused by fluctuations polysulfuride bonds (S-S) in chains (-S-S-). ${ }^{4}$ Apparently, sulfur enters into structure of a glass as new anion fragment essentially changing IR-spectra of the given glasses. Obviously, there is an exchange interaction sodium sulfide with phosphate of a making grid of a glass, are formed in structure of a glass polysulfuride groupings, which promotes stabilization of glassy condition. In pseudo-triple system while increasing of the contents $\mathrm{MgF}_{2}$ in structure of a glass will; be formed fluoride structural units of a type $\mathrm{MgF}_{4}, \mathrm{MgF}_{6}$, which will the function of glassforming, expanding the area of glassformation.

Distinctive feature of thioflourophosphate glasses are the high values of coefficient of linear thermal expansion (CLTE), which is increased in process of increase of the contents of sulfide grid of the glasses reaching $260 \times 10^{-7} \mathrm{~K}^{-1}$, perspective for welding with aluminum. At the some time the temperature of glasses formation is decreasing, viscosity of a glass, as well as energy of activation of viscous flux, and activation entropy. Thioflourophosphate glasses enriched with alkaline-earth flourides elements are rather refractory. Replacement of sulfur by flouring to increasing the temperature to the viscosity $10^{13}$ poise and free energy of activation of viscous flux. They are stable at ambient humidity and can be used without further protection of the surface.

\section{SUMMARY}

In the structure of synthesized glasses exchange interaction of sodium sulfide with glass net phosphate composed takes place, and polysulfure groupings are formed, which promote widening of glassformation region and stability to crystallization. The characterizing peculiarities of synthesized glasses are high indexes of coefficient of linear thermal expansion with low spreading temperature, reaching $260 \times 10^{-7} \mathrm{~K}^{-1}$, perspective for welding with aluminum.

\section{REEERENCES}

1. N.M. Haroutunian, A.A. Margarian, V.D. Khaliev, J. Arm.Chem.. 33, 7 (1980) 
2. O.A. Bonn, P.V. Geld, Metallurgia, 363(1966)

3. C.K. Khorgeneen, J.Progr.Inorg.Chem., 4, 73(1962)

4. K.Nakamoto, Pub.MIR, (1966) 